\title{
The influence of using platelet rich plasma for post-extraction wound healing process
}

\author{
Franky Oscar*, Sunardi Mangundjaja*, Makmuri Yusuf**, Bambang Pontjo*** \\ *Department of Oral and Maxillofacial Surgery Faculty of Dentistry Universitas Padjadjaran \\ Hasan Sadikin Hospital-Bandung, West Java, Indonesia \\ ** Department of Pathology Anatomy Faculty of Medicine Universitas Padjadjaran \\ Hasan Sadikin Hospital-Bandung, West Java, Indonesia \\ ${ }^{* * *}$ Department of Pathology Anatomy Faculty of Veterinary Medicine Bogor Agricultural Institute
}

(IPB)

\section{ABSTRACT}

Wound healing process characterized by specific processes of inflammation, proliferation, and maturation. It was coordinated by the regenerating and healing factors, including growth factor. Platelet rich plasma was a blood component that separated from blood cell plasma, which contain a lot of growth factors for increased wound healing. The objective of this research was to observe the effect of application of platelet rich plasma for wound healing. The true experimental factorial design research was done to 24 rabbits (Oryctolagus cuniculus) which have been performed tooth extraction and application of platelet rich plasma. These rabbits were terminated on $3^{\text {rd }}, 7^{\text {th }}$, and $14^{\text {th }}$ day, and the lower jaw region where the tooth had been extracted were cropped stained with hematoxylin-eosin for fibroblast and collagen histopathology examination. Based on ANAVA statistical analysis, the mean of fibroblast on experimental group was $52.00 \pm 19.18$ higher than the control group $24.83 \pm 10.46$. Statistical tests showed a significant result of platelet rich plasma application to fibroblast amount $(p<0.001)$. Collagen mean on experimental group was $30.25 \pm 9.33$ higher than the control group $13.75 \pm 6.96$. It was significant statistically $(p=0.001)$. The conclusion of this research that wound healing process was influenced by the application of platelet rich plasma.

Key words: Fibroblast, collagen, platelet rich plasma.

\section{INTRODUCTION}

Wound healing is a specific process which involved various factors. The mechanism involved inflammation process, matrix formation for cell regeneration, and wound edge contraction. Its main purpose is to get wound healing process through the perfect cells regeneration. ${ }^{1}$

One of the identified factors which may influence the wound healing process is the growth factor. The growth factor located in blood. When a centrifugation carried out against blood with specific amount of speed, there will be segments of blood components, such as blood cells and the plasma which contained the platelet rich plasma (PRP) including the growth factor. The growth factor separated from other blood components will be located in the upper layer of blood segments. ${ }^{2-3}$

Correspondence author: Franky Oscar, Department of Oral and Maxillofacial Surgery Faculty of Dentistry Universitas Pa djadjaran JIn. Sekeloa Selatan No. 1 Bandung, West Java-Indonesia, Tel.IFax: +6222-2504985/2532805 
There are various kinds of cells in wound healing; growth factor and other proteins which interaction of each other will create a fast and efficient wound healing. Scientists carried out several studies regarding the role of growth factor in wound healing. When a wound occurred and damaged veins and tissues below the subendothelial, the platelet would merge and created a collagen protein. When the platelet attached to the collagen, granules of adenosine diphosphate, serotonin and thromboxane, which contributed the haemostatic mechanism and blood coagulation cascade, would be released. Other platelets would contribute the platelet plug formation. This plug supported by a protein fiber web that could not been dissolved, known as fibrin web. These platelets would actively produce some growth factors involved in wound healing. The two most important growth factors were the platelet derived growth factor (PDGF) and the transforming growth factor- $B$ (TGF-B). Each growth factor had a unique function in wound healing. ${ }^{4}$

Growth factor in platelet rich plasma initiated from the hematoma phase. The hematoma phase is the first phase of wound healing process. The most important growth factors are the PDGF and TGF- $B$ which function is to initiate the proliferation of messenchimal cells, to activate macrophage, and to support the angiogenesis process. ${ }^{5}$

Growth factor is a biological mediator which contains different receptors in cell and tissue repair, including the cell proliferation and differentiation. The high concentration of growth factor will help the healing process of soft tissues and production of new bones. ${ }^{6}$

Histological, wound healing undergoes three phases. The first phase is the catabolic period, followed by proliferative phase that occurs approximately 14 days after injury, and the last is the reparation phase and reorganization phase that occur for months later. There are many cells and veins in the proliferation phase. A good cell metabolism will enhance the cell differentiation, migration, and new matrix formation. Platelet derived growth factor have major role in this phase; it activates the macrophage and angiogenesis, fibroblast and preosteoblast proliferation through hameostactic and mitotic activity initiation. Platelet rich plasma is derived from blood separation using a centrifugation to obtain a concentration of 300 to $500 \%{ }^{6}$

Platelet releases the agents or mediators that will enhance the tissue repair and influence the vascular activity and other blood cells in angiogenesis and inflammation processes. Platelet contains the PDGF, TGF- $B$, and VEGF growth factor, as their main functions will clinically produce the positive effects of wound healing and tissue regeneration. $^{7}$

Several components mechanism in wound healing was still could not be explained completely. In this research, the activity and the number of fibroblast, as well as the collagen production through histopathology assay using haematoxylineosin (HE) would be observed. As the application of the platelet rich plasma locally into the tooth sockets, the fibroblast activity and the collagen production that enhance the wound healing process was expected.

\section{MATERIALS AND METHODS}

This research was a pure experimental study random design factorial pattern. The research conducted at the Pathology Department of Veterinary Faculty of Institut Pertanian Bogor and the Pathology Anatomy Laboratory of Hasan Sadikin Hospital, Faculty of Medicine Universitas Padjadjaran Bandung between October-November 2008.

Subject was 24 New Zealand rabbits (Oryctolagus cuniculus). The rabbits were divided into two different groups, which are: no treatment group, which comprised of rabbits that had their lower primary tooth extracted; and the treatment group, which had the same extraction of tooth but additional platelet rich plasma (PRP) was applied to the sockets.

After the treatment of both groups, on the $3^{\text {rd }}, 7^{\text {th }}$, and $14^{\text {th }}$ day, rabbit necroption was carried out, and the lower jaw region where the tooth had been extracted were cropped, and prepared with haematoxylin-eosin, under the microscopic observation with $400 x$ magnification (10x ocular lens and 40x objective lens). Calculation of fibroblast and collagen cells amount on the area where the tooth had been extracted with a great view of unit area in each case. Treatment, time and interaction were tested using ANAVA factorial pattern. 


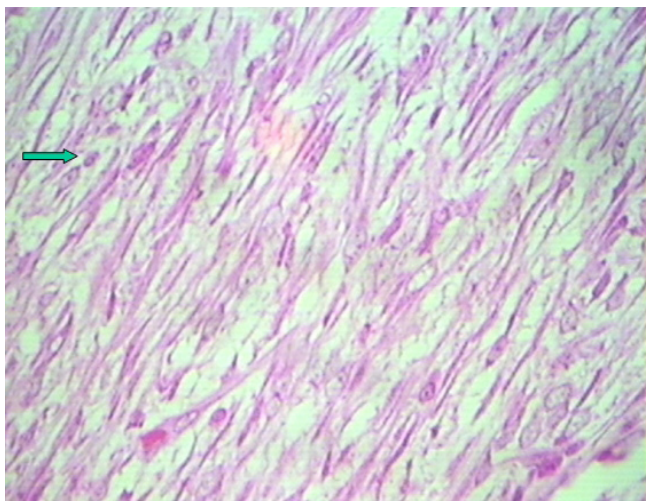

Figure 1. The photomicrograph result of fibroblast cells in the treatment group on $7^{\text {th }}$ day.

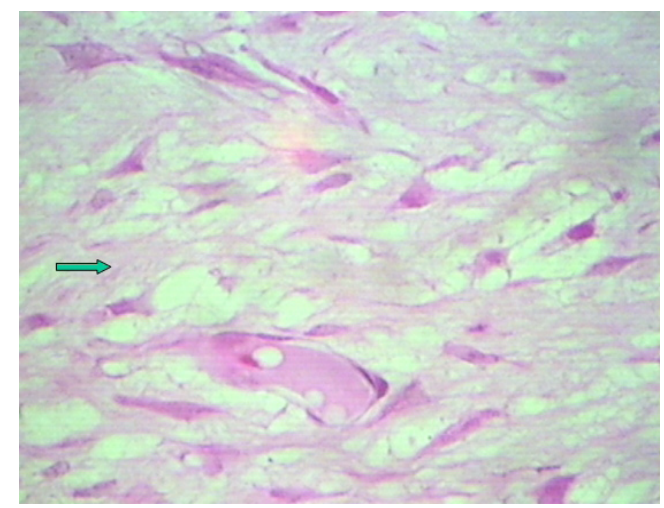

Figure 2. The photomicrograph result of fibroblast cells in the control group (arrow = fibroblast cell).

\section{RESULTS}

The mean of fibroblast in the treatment group with platelet rich plasma applied locally into the sockets was $52.00 \pm 19.18$. Those are higher than the control group which was $24.83 \pm$ 10.46 (Fig. 1 and 2). Treatment using the platelet rich plasma to the number of fibroblast cells was statistically significant Similarly, it also happened in the time period toward the number of fibroblast that was statistically significant Interaction between the treatment group of platelet rich plasma application with the healing period was statistically significant.

The mean of collagen in the treatment group with platelet rich plasma locally into the sockets was $30.25 \pm 9.33$. It was higher than the control group which was $13.75 \pm 6.96$ (Fig. 3 and 4). Usage of the platelet rich plasma against the number of collagen was statistically significant. The effect of time period against the number of fibroblast was statistically no significant. The interaction

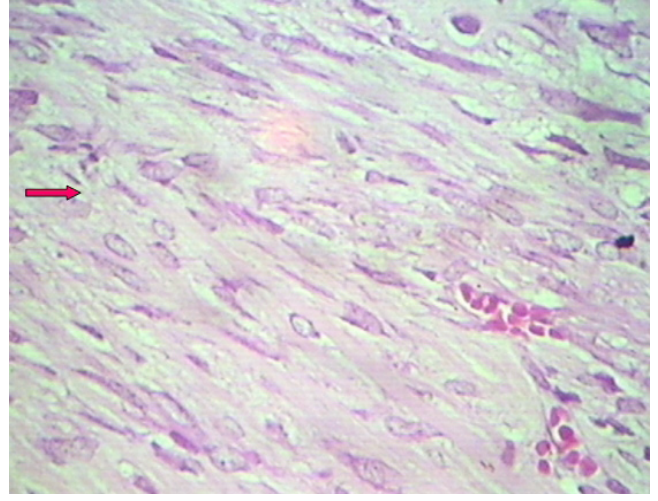

Figure 3. The photomicrograph result of collagen fiber in the treatment group on $14^{\text {th }}$ day.

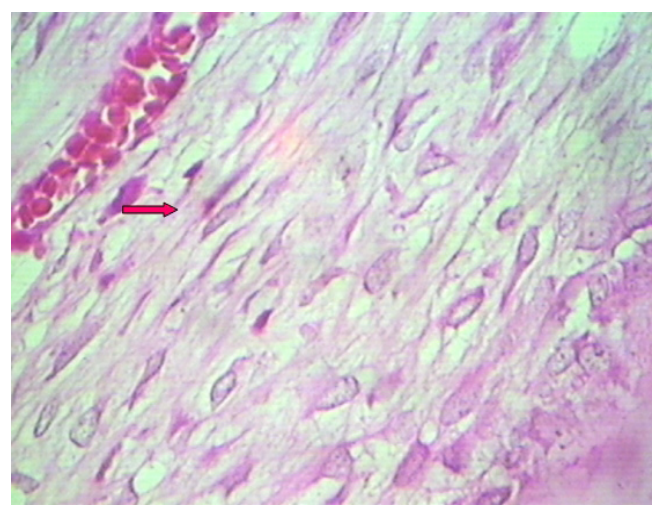

Figure 4. The Photomicrograph result of collagen fiber in the control group on $14^{\text {th }}$ day (arrow = collagen).

between the usage of platelet rich plasma with the healing period was statistically no significant.

\section{DISCUSSION}

Wound healing of tooth socket initiated as the veins inside the gum, periodontal ligament, and alveolar crest area damaged. This occurs as a haemostatic process which will cause the formation of blood coagulation that covers the sockets. This wound healing process needed cell migration, epithelial, and collagen synthesis in great number due to the space between wound edges. ${ }^{8-10}$

Blood components which released as the breakdown of vein occurred as a result of tooth extraction were the plasma and blood cells. Thrombocyt also played an important role in forming blood clot to plug the broken veins. Damaged thrombocyt will release thrombokinase that will transform prothrombin into thrombin, and the thrombin then will transform fibrinogen into 
fibrin. Blood clot comprises of thrombocyt clot and fibrin web. One significant function of the blood clot served as a source of growth factors, those are transforming growth factor alpha and beta (TGF-a and $-B$ ), epidermal growth factor (EGF), platelet derived growth factor (PDGF), fibroblast growth factor (FGF), and insulin growth factor (IGF). Beside of growth factor, there are also mediators derived from thrombocyt such as fibrinogen, fibronectin, thrombospondin, serotonin, and several enzymes such as elastase, collagenase, hydrolase and thrombokinase. Growth factor and cytokines function as a chemotactic and mitogenic factors for inflammation and fibroblast. ${ }^{11,12}$ In this study, as seen on microscopic observation result on day 3 of treatment group or control group, several veins were broken down due to tooth extraction. In this observation, the number of fibroblast cells began to rise. Fibroblast cells and endothelial cells from veins around the socket wall would run to the blood clot and form new young connective tissue which was the beginning of wound healing process.

The number of fibroblast cells in the treatment group were increased (approximately 28.50) compared to the control group (12.00) due to the usage of platelet rich plasma (PRP) into the extracted tooth socket. These platelets concentrated in PRP contained more growth factors such as platelet derived growth factor, insulin-like growth factor, and transforming growth factor that would accelerate and support tissue regeneration. Those growth factors would move the fibroblast cells to concentrate around the wound. The fibroblast would then form an extra cellular matrix and eventually formed collagen. Before that, the fibroblast cells would form and excrete the tropocollagen molecules. These tropocollagen molecules would connect each other and formed collagen fiber so that it would protect the wound. ${ }^{13-15}$

In the day 7 observations, the number of fibroblast cells or the collagen fibers increased more in the treatment group compared to the control group. In the treatment group, the mean of fibroblast cells was 70.75 , higher than the control group with mean of 31.50 . It is the same with mean of collagens in the treatment group was 25.00 compared to the control group was 12.75 . This influenced by the mediators released by the thrombocyt and macrophage such as fibroblast growth factor and epithelial growth factor. The additional growth factors in PRP increased the concentration of growth factors around the extracted tooth wound, so that the proliferation of fibroblast cells would also increased compared with the control group. The fibroblast cells would undergo the collagen synthesis actvity in order to form a granulation tissue. The number of increased fibroblast cells in the treatment group would cause the number of collagen fibers, which synthesis were influenced by the fibroblast cells, also increased compared to the control group. ${ }^{14,15}$

Under microscopic observation at the $14^{\text {th }}$ day, there was decreased number of fibroblast cells compared to the observation on $7^{\text {th }}$ day, either it was in the treatment group or in the control group. The fibroblast cells underwent lysis, in a path of degradation of fibroblast cells by the collagenase enzyme produced by thrombocyt, while the collagen synthesis stimulated by interleukin-1, fibronectin, epithelial growth factor and transforming growth factor. In contrast, the number of collagen fibers on the $14^{\text {th }}$ day increased, either in the treatment group or the control group compared with $7^{\text {th }}$ day.

The number of fibroblast cells on the $7^{\text {th }}$ day showed the highest, since after the $7^{\text {th }}$ day there were more fibroblast cells which synthesized tropocollagen into collagen, so there would be decreased number of fibroblast cells on $14^{\text {th }}$ day. In addition, on the $14^{\text {th }}$ day, the number of collagen was in the highest number (approximately 35.50) compared with the control group (14.75).

\section{CONCLUSION}

There was an effect of a platelet rich plasma application into sockets by increasing of the number of fibroblast and collagen after tooth extraction. The platelet rich plasma application into sockets with healing period was statistically no significant. The interaction of platelet rich plasma application into sockets with the healing period after tooth extraction was statistically no significant.

\section{REFERENCES}

1. Cohen K, Diegelmann RF. Wound care and wound healing. In: Schwartz. Principles of 
surgery. $7^{\text {th }}$ ed. New York: McGraw Hill; 1999.

2. Carlson NE, Roach RB. Platelet rich plasma. J Am Dent Assoc 2002;133(10):1383-6.

3. Ivan $C$. The use of platelet rich plasma in oral surgery. J IMAB-book 22005.

4. Anitua E, Andia I. Autologous platelets as a source of protein healing and tissue regeneration. J Thromb Haemost 2004;91:415.

5. Ward BB, Edwards SP, Feinberg SE. Healing of traumatic injuries. In: Fonseca RJ. Oral and maxillofacial trauma. Philadelphia: WB Saunders; 2005. p. 25-67.

6. Diegelmann RF, Evans MC. Wound healing: an overview of acute, fibrotic and delayed healing. Frontiers in Bioscience 2004;9:283-9.

7. Hupp JR. Wound repair. In: Peterson LJ. Contemporary oral and maxillofacial surgery. $4^{\text {th }}$ ed. St. Louis: Mosby; 2003. p. 49-62.

8. Raja SV, Naidu ME. Platelet rich fibrin: evolution of a second generation platelet concentrate. Indian J Dent Res 2008;19:42-8.

9. Jameson CA. Autologous platelet concentrate for the production of platelet gel. Labmedicine 2007;38:39-42.

10. Arikan F, Becerik S, Sonmez S, Gurhan I. Effect of platelet rich plasma on gingival and periodontal ligament fibroblast: new in-vitro growth assay. Braz J Oral Sci 2007;6:1432-8.

11. Frechete JP, Martineau I, Gagan G. Platelet rich plasma: growth factor content and roles in wound healing. J Dent Res 2005;84:434-9.

12. Issa JPM, Tiossi R, Mello AS, Lopes RA, Matteo MAS, Iyomasa MM. PRP: A possibility in regenerative therapy. Int $\mathrm{J}$ Morphol 2007;25(3):587-90.

13. Adler SC, Kent KJ. Enhancing wound healing with Growth factors. Facial Plast Surg Clin N Am 2002;10:129-46.

14. Rieman P. Platelet-rich plasma reducing bleeding, speeds healing. Cosmetic Surgery Times 2000:38.

15. Gharaee-Kermani M, Phan SH. Role of cytokines and cytokine therapy in wound healing and fibrotic diseases. Curr Pharm Design 2001;7:1083-103. 